\title{
PRIVATIZATION IN A SMALL OPEN ECONOMY WITH IMPERFECT COMPETITION
}

\author{
Arghya Ghosh \\ Email: a.ghosh@unsw.edu.ac \\ University of New South Wales \\ Sydney, NSW 2052 \\ Australia
}

Partha Sen

Email: partha@econdse.org

Delhi School of Economics

University of Delhi

Working Paper No. 195

Centre for Development Economics

Department of Economics, Delhi School of Economics 


\title{
Privatization in a Small Open Economy with Imperfect Competition
}

\author{
Arghya Ghosh* \\ University of New South Wales \\ Sydney, NSW 2052 \\ Australia \\ Partha Sen \\ Delhi School of Economics \\ New Delhi 110007 \\ India
}

\begin{abstract}
We look at privatization in a general equilibrium model of a small, tariff-distorted, open economy. There is a differentiated good produced by both private and public sector enterprises. A reduction in government production in order to cut losses from such production raises the returns to capital and increases the tariff revenue, which are welfare improving. However, privatization also leads to lower wages and possibly fewer private brands. This lowers workers' welfare, which may make privatization politically infeasible. Privatization can improve workers' welfare with complementary reforms, e.g., attracting foreign investment or trade liberalization.
\end{abstract}

JEL Classification: H41, F12, L32

Keywords: public sector enterprise, privatization, foreign investment, trade liberalization, monopolistic competition. 


\section{Introduction}

Discouraged by the poor performance of public sector enterprises (PSEs), governments in several developing market economies - e.g., India, Chile, Egypt, Mexico, Philippines, Turkey-have attempted to withdraw from the production of "private" goods. ${ }^{1}$ Does the withdrawal of government from production-which we refer to as privatization in the remainder of the paper-improve welfare? We address this question in a simple two-factor, two-sector, general equilibrium, open economy framework where the sector comprising of public enterprises and private firms is imperfectly competitive. ${ }^{2}$

We find that privatization, if pursued alone, can often reduce the welfare of the workers. This might make privatization politically infeasible in democratic developing economies since workers often constitute a majority or the support base of the ruling party. Privatization can, however, be politically feasible (i.e., welfareimproving for workers) with complementary reforms. For example, an increase in foreign investment in conjunction with privatization improves the workers' welfare. Trade liberalization, pursued along with privatization, can improve workers' welfare under certain conditions. ${ }^{3}$

Our analysis, a brief sketch of which is given in section 1.1, contributes to the ongoing debate on privatization in developing countries in at least three important ways, which we discuss below. Specific contributions are discussed in section 1.2.

First, although the existing literature on privatization based on a partial equilibrium framework (see section 1.2 below for a review of this literature) offers some insights into the debate, the effect of privatization on workers' wages, and more generally on factor returns - which lie at the heart of the privatization debate-is missing. By explicitly incorporating factor markets for labor and capital into our general equilibrium open economy framework, we offer a richer analysis and show

\footnotetext{
${ }^{1}$ Various explanations have been offered for the lackluster performance of public enterprises, e.g., a distorted incentive structure, the plurality of principals and objectives which often results in inefficient utilization of resources, over-employment, and low productivity. There is a vast body of empirical literature confirming the inefficiency of public enterprises in developed as well as developing countries. See, e.g.,Galal et al. (1994) and Majumdar (1998). For a survey of the empirical findings, see Megginson and Netter (2001).

${ }^{2}$ The presence of imperfect competition together with increasing returns to scale provides a meaningful role of firms. The imperfectly competitive structure is a good description of markets in the less developed countries (see Nellis and Kikeri, 1989, p. 663).

${ }^{3}$ It is important to note that in an imperfectly competitive model such as ours, trade liberalization alone does not necessarily improve welfare. Nor, for that matter, does capital inflow.
} 
that indeed, privatization can reduce wages, which in turn can lower welfare.

Second, most studies on privatization referred to in section 1.2 consider a short-run set up with a fixed number of firms. Hence, they are not well suited to addressing another important concern — the effect of privatization on the domestic market structure. By explicitly incorporating entry-exit considerations into our framework we address this concern and find that a reduction in public sector production does not necessarily encourage the entry of private producers. In other words, private producers, rather than entering to fill the void created by the contraction of PSEs, might exit, which can reinforce (partial) deindustrialization.

Third, focusing on a tariff-distorted open economy (instead of a closed economy) allows us to examine the effect of a combination of policies-e.g., privatization and foreign investment, privatization and trade liberalization-which typically comes with a reform package. Apart from generating a rich set of possibilities, the open economy description is also more realistic. Over the last two decades, developing countries embarking on privatization were also usually the ones lowering their tariffs (see Sachs and Warner, 1995). ${ }^{4}$ By analyzing trade liberalization, privatization, and capital inflows in a unified general equilibrium framework, we hope to contribute to a better understanding of the complementarities (or the lack thereof) between these policies.

\subsection{A Preview of the Model and Results}

Adapting a monopolistic competitive model along the lines of Venables (1982) and Helpman and Krugman (1985), we focus on a small tariff-ridden open economy. It produces (and consumes) a homogenous good and a number of differentiated brands, and imports a range of foreign brands. The homogenous good, produced under constant returns to scale, is exported whereas the differentiated domestic brands, exhibiting increasing returns, are non-traded and are produced by private and public sector firms.

A key difference between a public sector enterprise and a private firm is in the

\footnotetext{
${ }^{4}$ Sachs and Warner (1995) label a country as closed or open based on a combination of criteria (e.g., tariff rate, exports to GDP ratio, black market premium etc.). They also provide timings for liberalization, i.e., when the countries switched from being closed to open. Their classification shows that among the countries (mentioned earlier in the Introduction) which embarked on privatization, Chile opened up in 1970s, Mexico, Philippines and Turkey in late 1980s. India qualified as open in the mid-1990s. Egypt was the only one never considered as open.
} 
objective function. Private firms maximize profit. On the other hand, public firms typically have non-profit motives. Due to political influence, PSEs often employ inefficiently high amount of labor. As Boycko, Shleifer and Vishny (1996) write: "while excess employment is not the only politically demanded inefficiency of state firms it is surely the most commonly noted one." They construct a politician's objective function which reflects that the politician prefers higher labor spending in the PSEs. In a similar spirit, to capture the non-pecuniary benefit from higher employment in public firms, we assume that a public firm maximizes its own profit plus a fraction of wage bill paid to its workers. Effectively, this implies that a public firm receives a wage subsidy. The presence of implicit wage subsidy leads to a lower capital-labor ratio in PSEs compared to their private counterparts.

We model privatization as a reduction of the fractional weight on wage bill. This acts as a reduction of wage subsidy to public firm. For a wide range of parameterizations, the reduction in subsidy leads to a contraction of the PSE. Due to its use of labor-intensive techniques, this contraction in turn gives rise to an excess supply of labor, which in our full employment model lowers wages. Indeed, the situation can be even worse. In equilibrium, if the PSEs use the most labor-intensive technique while the private brands producers use the least labor-intensive one then the production of private differentiated goods might decrease. Domestic private producers might exit from the differentiated goods sector and thus privatization may fail to encourage the entry of more private producers-something it was implicitly expected to do. The reduction in the number of available varieties (i.e., fewer private brands), combined with lower wages implies that unless accompanied by other policies, the privatization program will generally reduce the welfare of workers.

The immiserization of workers poses a problem in terms of political viability of the privatization program since in a large number of democratic developing countries, workers constitute the majority and/or the support base of the ruling parties. So, even if privatization is welfare improving in overall terms (which may not be the case), it might not be politically viable in the absence of complementary reforms. ${ }^{5}$ Are there complementary reforms which can be pursued in conjunction with privatization to prevent a reduction in workers' welfare?

\footnotetext{
${ }^{5}$ For discussions on the importance of political viability in privatization programs, see World Bank
} (1995). Also see Clarke and Cull (2005) in this regard. 
Given that ours is an open economy model, two policy choices seem naturallowering of trade restrictions and/or encouraging foreign investment. Increased capital inflows lead to an increase in the number of brands (via the entry of private producers) as well as an increase in wages, which in turn improves welfare. Although trade liberalization, by expanding the relatively labor-intensive homogenous goods sector, increases wages, it comes at the expense of reduced variety. Thus trade liberalization, if pursued along with privatization, improves welfare only if the effect of a decline in variety on welfare is not too strong.

\subsection{Related Literature}

Our paper is manifestly related to the trade literature on imperfect competition in general, and on monopolistic competition in particular. Though some particular aspects of the model-e.g., optimal tariffs (see Venables, 1982) and the welfare effects of capital inflows - have been analyzed (see, e.g., Sen et al., 1997; Chakraborty, 2001), the introduction of government production in a tractable fashion is novel. More importantly, incorporating government production allows us to conduct a simultaneous investigation of three important issues - privatization, trade liberalization, and foreign investment - which are often mentioned in the same breath in the financial press but rarely analyzed in a rigorous unified framework.

The public economics literature on mixed oligopoly, which typically uses a partial equilibrium set up, asks the same question as we do-namely, when does privatization improve welfare ${ }^{6}$ This literature offers several reasons why privatization might improve welfare. DeFraja and Delbono (1989) show that in the presence of increasing marginal costs (i.e., decreasing returns to scale), privatization, by reducing the scale of production of former PSEs, improves production efficiency, which can improve welfare. Using a spatial model of product differentiation, Cremer

\footnotetext{
${ }^{6}$ Apart from the mixed oligopoly literature, there are at least three distinct strands of literature on privatization. See Roland (2000) for a comprehensive analysis of privatization in transition economies. Despite providing insights that are generally applicable, the absence of markets in the pre-transition period makes it difficult to compare the findings across periods, and hence we refrain from discussing this literature. We also abstract from the incomplete contract-based literature (see Hart et al., 1997; Schmidt 1996) of privatization, which focuses on the incentives arising from ownership (private versus public). This brings a new angle to the privatization debate (i.e., ownership), which has traditionally focused on market competition. Nevertheless, it is fair to say that this is probably more appropriate in the context of privatization of public provision in developed countries (e.g., schools, hospitals, prisons etc.). Finally, there is a third strand of literature based on a principal-agent model which focuses on managerial incentives and monitoring problems. See, e.g., Barros (1994), De Fraja (1993).
} 
et al. (1991) show that the presence of a public firm could result in product configuration which is too concentrated. Privatization, by reducing concentration, can improve welfare. Building on a Hotelling-duopoly framework and introducing endogenous cost differentials between public and private enterprises, Matsumura and Matsushima (2004) show that the private firms are indeed more efficient than the public ones. However, the increased efficiency comes at the expense of excessive investment in cost-reducing activities. Privatization in their framework improves welfare by mitigating the loss arising from excessive cost-reducing investments.

Anderson et al. (1997) provide an important potential benefit of privatization, which only manifests itself in the long run (i.e., with free entry). In the short run, with a fixed number of firms, the presence of a public sector firm lowers prices, which increases welfare. However, in the long run, the lower prices of public firms act as entry deterrent and, consequently, fewer varieties are offered in the market. Anderson et al. show that privatization, by increasing the number of varieties, can lead to higher welfare provided the public firm was incurring losses (before privatization). ${ }^{7}$ Free entry of private producers has also been discussed in the context of partial privatization in Matsumura and Kanda (2005) and Fujiwara (2007). Both these works show that in the presence of free entry, the results with a fixed number of private firms might no longer hold.

Entry considerations play an important role in our framework as well. But because of the absence of factor markets, the framework used in the abovementioned papers cannot be used to explore some of the key issues and concerns-e.g., fall in wages and/or a rise in unemployment, deindustrialization, conflicts across factor owners - associated with the privatization programs, especially in developing countries. Our two-factor, two-sector, general equilibrium framework, to which we turn now, exploits an important channel through which the contraction of the public sector works - the economy-wide reallocation of resources and subsequent effects on factor returns, entry, and production.

As far as we are aware, Beladi and Chao (2006) is the only paper that considers labor market issues in the context of privatization. In a dual economy (but a closed one), they show that an increase in private ownership leads to an increase in urban

\footnotetext{
${ }^{7}$ The papers on mixed oligopoly discussed here are mainly theoretical in nature. For empirical analysis on mixed oligopoly, see Barros and Modesto (1999). They investigate the regulatory role of public firm in the Portuguese banking sector, which consists of private as well as public firms.
} 
employment in the short run. In the long run, the unemployment problem becomes less severe as capital moves to the rural sector. Unlike their framework, ours is a full employment general equilibrium setting. The key difference, however, is that ours is an open economy set up in contrast to the closed economy setting considered in Beladi and Chao (2006). Considering an open economy allows us to examine the role of complementary reforms - trade liberalization and freer capital inflows - in generating political support for privatization.

\section{The Model}

Consider a small tariff-ridden open economy comprising of $\bar{L}$ workers and $\bar{K}_{d}$ capitalists. Each worker has one unit of labor while each capitalist has one unit of capital. ${ }^{8}$ The workers and the capitalists have identical preferences.

\subsection{Consumers}

Each individual $i$ maximizes an upper-tier Cobb-Douglas utility function given by

$$
U_{i}=X_{i}^{\alpha} y_{i}^{1-\alpha}
$$

subject to the budget constraint

$$
y_{i}+P X_{i}=z_{i},
$$

where, $y_{\mathrm{i}}, X_{i}$, and $z_{i}$ denote, respectively, the amount of individual $i$ 's (i) consumption of the (numeraire) homogenous good $y$, (ii) consumption of an aggregate quantity index of differentiated goods $X$ (whose price is $P$ ), and (iii) income. Apart from factor earnings, $z_{i}$ includes a share of tariff revenues (which is rebated to individual $i$ ) and is net of lump-sum taxes that are used to cover losses (if any) of the PSEs.

The quantity index (or alternatively the sub-utility function of the DixitStiglitz type) $X_{i}$, defined below, captures consumers' love for variety:

$$
X_{i}=\left(\sum_{k=1}^{n} x_{k i}^{\frac{\sigma-1}{\sigma}}+\sum_{j=1}^{n^{*}} x^{*}{ }_{j i}^{\frac{\sigma-1}{\sigma}}+s^{\frac{\sigma-1}{\sigma}}\right)^{\frac{\sigma}{\sigma-1}}
$$

where $x_{k i}, x_{j i}^{*}$, and $s$ denote, respectively, the amount of individual $i$ 's consumption of

\footnotetext{
${ }^{8}$ The assumption that each capitalist owns one unit of capital captures the fact that each capitalist is small. However, this assumption is only for simplification and nothing substantial hinges on it.
} 
a domestic private brand $k$, a foreign brand $j$, and the public brand. Following the literature on mixed oligopoly we assume that there is a single public brand. The assumption is not crucial for our results, but it simplifies the algebra. $\sigma>1$ is the elasticity of substitution between brands (below in equations (7) to (9) it is the elasticity of demand facing each producer). The number of domestic private brands and foreign brands are given by $n$ and $n^{*}$ respectively. The price index corresponding to $X$ is

$$
P=\left(\sum_{k=1}^{n} p_{k}^{1-\sigma}+\sum_{j=1}^{n^{*}} p_{j}^{f^{1-\sigma}}+q^{1-\sigma}\right)^{\frac{1}{1-\sigma}}
$$

where $p_{k}, p_{j}^{f}$, and $q$ are, respectively, prices of a domestic private brand $k$, an imported brand $j$, and the public brand. Note that the price of an imported brand, $p_{j}^{f}$, is inclusive of tariffs, i.e., $p_{j}^{f}=(1+t) p_{j}{ }^{*}$ where $p_{j}{ }^{*}$ is the international price of the $j$ th foreign brand and $t>0$ is the ad-valorem tariff rate.

The utility maximization exercise (maximizing (1) subject to (2)) followed by aggregation across $\bar{L}+\bar{K}_{d}$ consumers yields the expenditure shares of the homogenous goods and the differentiated goods as follows:

$$
\begin{aligned}
& y=(1-\alpha) z, \\
& P X=\alpha \quad z,
\end{aligned}
$$

where $y, X$, and $z$ denote, respectively, the aggregate consumption of homogeneous good, aggregate quantity index of differentiated good, and national income. Next, maximizing the sub-utility function $X_{i}$, given by (3), subject to the constraint that the sum of expenditure on all brands has to be less than or equal to $P X_{i}$, yields the demands for individual brands by each consumer $i$. Adding all consumers' demands yields the aggregate demand for these brands as follows:

$$
\begin{gathered}
x_{k}={p_{k}}^{-\sigma} P^{\sigma-1} \alpha z, \\
x_{j}^{*}=\left((1+t) p_{j}^{*}\right)^{-\sigma} P^{\sigma-1} \alpha z, \\
s=q^{-\sigma} P^{\sigma-1} \alpha z .
\end{gathered}
$$

Hereafter we will focus on a symmetric equilibrium where each private firm sets the same price $p_{k}=p$, and produces the same amount of output $x_{k}=x$. The same is true for foreign varieties, i.e., $x_{j}^{*}=x^{*}$. Following the standard practice in the small open economy literature with imperfect competition (see, e.g., Venables, 1982; Sen et 
al., 1997; Chakraborty 2001), we assume that the price and the number of foreign brands are exogenously given.

\subsection{Firms}

The homogenous good, whose output is denoted by $Y$, is produced under constant returns to scale using labor and capital. Competition, together with the constant returns to scale technology, implies the equality between price (unity for the numeraire) and marginal cost:

$$
a_{L Y} w+a_{K Y} r=1
$$

where $a_{i j}$ denotes the amount of factor $i(=L, K)$ utilized in producing a unit of $\operatorname{good} j$, and $w$ and $r$ are, respectively, wages and returns to capital. ${ }^{9}$

\section{Private brands}

The production of each private brand consists of two components - a variable cost and a fixed cost. Both components use a CRS technology (different from the ones used in the homogenous goods sector) employing labor and capital. Profit maximization for each private brand implies the mark-up pricing rule:

$$
a_{L x} w+a_{K x} r=p\left(1-\frac{1}{\sigma}\right) .
$$

Free entry of private firms in the differentiated goods sector implies that private profits are zero in equilibrium. Thus for each private brand, the excess of revenue over total variable cost (as reflected in (11)) exactly covers the fixed costs incurred. This gives

$$
a_{L F} w+a_{K F} r=\frac{p x}{\sigma},
$$

where $a_{i F}$ denotes the amount of factor $i(=L, K)$ used as fixed input. Though each component—variable or fixed - exhibits CRS, the presence of the fixed cost itself implies the presence of increasing returns to scale in the differentiated goods sector.

\footnotetext{
${ }^{9}$ When the production function of the differentiated good sector is homogenous of degree one, its cost function can be written as $c^{x}(w, r) x$, where $c^{x}(w, r)$ denote the unit cost function of $x$. Wong (1995) and Feenstra (2003) adopt this formulation. We followed Jones (1965) in using $\mathrm{a}_{\mathrm{Li}} \mathrm{W}+\mathrm{a}_{\mathrm{Ki}} \mathrm{r}$ instead of $\mathrm{c}^{\mathrm{x}}(\mathrm{w}, \mathrm{r})$. The two approaches are equivalent.
} 
We assume that the capital intensities for the fixed and the variable components are the same, i.e., $\frac{a_{K x}}{a_{L x}}=\frac{a_{K F}}{a_{L F}}$. This assumption used elsewhere in the literature (see e.g., Antras 2003, p. 1382) makes the total cost function homothetic. In particular, using (11) and (12), this assumption implies that $x$ is constant.

\section{Public sector enterprise (PSE)}

While a private firm maximizes profit, a public sector enterprise often has non-profit motives. Following Boycko, Shleifer, Vishny (1996) we assume that a PSE gets some additional benefit from higher spending on labor. The profit of the PSE is

$$
\pi_{g}=\left(q-w a_{L s}-r a_{K s}\right) s-w a_{L f}-r a_{K f}
$$

where $a_{i s}$ is the amount of input $i(=L, K)$ employed to produce one unit of $s$ and $a_{i f}$ is the labor employed in fixed component of $s$. In contrast to private firms that maximize profit, the PSE maximizes

$$
\pi_{g}+(1-\psi) w\left(a_{L s} s+a_{L f}\right)
$$

and $(1-\psi) w\left(a_{L s} s+a_{L f}\right)$ captures the non-pecuniary benefit to the public firm due to higher labor spending. The parameter $\psi \in(0,1]$ is a proxy for the degree of privatization of PSE. It increases as the extent of privatization increases. If the PSE is completely privatized $\psi=1 .^{10}$

This formulation suggests that a PSE behaves like a profit-maximizing firm except it faces a wage rate of $w \psi$ instead of $w$. The pricing condition corresponding to PSE is:

$$
a_{L s} w \psi+a_{K s} r=q\left(1-\frac{1}{\sigma}\right) .
$$

In equilibrium $\pi_{g}$ could be negative or positive. That is PSE can make losses or profits in our framework. If the PSE makes losses, we assume that it is paid for by

\footnotetext{
${ }^{10}$ The idea that a PSE attached a positive weight to something other than its own profit is borrowed from the mixed oligopoly literature. However, the papers in that literature assume that a PSE maximizes a weighted average of profit and welfare. As most papers use partial equilibrium framework, factor markets are typically not considered in that literature. Introduction of factor markets allow us to consider a scenario where a PSE attach a positive weight on wage bill for its employees. Positive weight in turn implies lower capital-labour ratio for PSEs which accord well with empirical evidence. See footnote 11.
} 
non-distortionary taxes on consumers. Positive profits of the PSE (if any) are distributed back to the consumers.

Two remarks are in order regarding loss-making PSEs. If $\psi=1$, so that there is no implicit subsidy, the PSE can make losses if $q s / \sigma$ does not cover the fixed $\operatorname{cost} w a_{L f}+r a_{K f}$. If $\psi<1$, then PSE can make losses even in the absence of fixed costs, if the following holds $\theta_{L s} \equiv \frac{a_{L s} w}{a_{L s} w+a_{K s} r}>\frac{1}{\sigma(1-\psi)}$.

As long as $\Psi<1$, capital intensity of the public brand will be lower than that in its private counterpart. That is, $\frac{a_{K x}}{a_{L x}}>\frac{a_{K s}}{a_{L s}}$. This is in line with the commonplace observation that PSEs employ labor-intensive techniques. ${ }^{11}$ Also, since the differentiated goods sector is presumably producing the importable manufacturing goods, we assume that the capital-intensity of the private brands is higher than the capital-intensity of the exportable homogenous good, i.e., $\frac{a_{K x}}{a_{L x}}>\frac{a_{K Y}}{a_{L Y}}$.

From the discussion above it follows that private brands use the most capital intensive techniques. Whether the capital-labor ratio is higher in the PSE or the homogenous goods sector depends on $\psi$. If $\psi$ is close to one, the public sector firm is almost a pure profit-maximizing firm and consequently the factor intensities are similar for the public brand and the private brand. Since $\frac{a_{K s}}{a_{L s}} \approx \frac{a_{K x}}{a_{L x}}$ and $\frac{a_{K x}}{a_{L x}}>\frac{a_{K Y}}{a_{L Y}}$ holds we have that $\frac{a_{K x}}{a_{L x}}>\frac{a_{K s}}{a_{L s}}>\frac{a_{K Y}}{a_{L Y}}$ when $\psi$ is close to one. On the other hand, if $\psi$ is close to zero, the wage bill is almost ignored as a cost in the PSE. In such cases $\frac{a_{K s}}{a_{L s}}<\frac{a_{K Y}}{a_{L Y}}$ will hold. We focus on the low values of $\psi$ such that the capital-labor ratios in different lines of production satisfy the following: $\frac{a_{K s}}{a_{L s}}<\frac{a_{K Y}}{a_{L Y}}<\frac{a_{K x}}{a_{L x}}$.

The factor-intensity rankings play important role in our framework. If the public brand is the least capital-intensive one (which is the case for small values of $\psi$ ),

\footnotetext{
${ }^{11}$ The higher labor intensity of PSEs is observed in the developing as well as developed countries. Testing for labor intensity of state-owned enterprises listed among the 500 largest non-US firms in 1975, 1985, and 1995, Dewenter and Malatesta (2001) find that the private firms use significantly less labor-intensive processes than state-owned enterprises.
} 
wages decrease and the number of varieties decline with an increase in the degree of privatization-see sections 3.1 and 3.2. On the other hand, if the homogenous good sector is most labor intensive (which holds for high values of $\psi$ ) an increase in the degree of privatization can still lower wages, but the number of private brands will always increase privatization. However, the key results of the paper-e.g., a worker's welfare decreases with privatization, an increased capital inflow (along with privatization) leads to improvement in a worker's welfare - can hold under a range of parameterizations.

\subsection{Market Clearing Equations}

The market clearing equations for labor and capital, respectively, are given by

$$
\begin{aligned}
& a_{L Y} Y+a_{L x} n x+a_{L F} n+a_{L s} s+a_{L f}=\bar{L} \\
& a_{K Y} Y+a_{K x} n x+a_{K F} n+a_{K s} s+a_{K f}=\bar{K}_{d}+\bar{K}_{f},
\end{aligned}
$$

where $\bar{L}$ and $\bar{K}_{d}$ are aggregate labor and domestic capital respectively in the economy. Given the paucity of domestic capital in small, tariff-ridden, developing economies, we assume, quite realistically, that the economy also employs foreign capital $\left(\bar{K}_{f}\right){ }^{12}$ In addition to the factor-market clearing equations, we have conditions (7), (8), and (9) which are the market clearing conditions for the private domestic brands, foreign brands, and public brands, respectively. Together, equations (7)-(9), (14) and (15) imply that trade is balanced, ${ }^{13}$ i.e.,

$$
Y-y=n^{*} p^{*} x^{*}
$$

The national income for this small open economy, denoted by $z$, is given by

$$
z=w \bar{L}+r \bar{K}_{d}+\pi_{g}+\operatorname{tn}^{*} p^{*} x^{*} .
$$

where the terms in the right-hand side of (17) respectively are wage income, capital income, PSE's profit and the tariff revenue. This completes the specification of the model. To obtain sharper results we will often focus on the case where the share of PSE's profit and tariff revenues in national income is small.

\footnotetext{
${ }^{12}$ We think of the amount of foreign capital as being exogenously given - it is more like a policy parameter. While this can be relaxed (e.g., by making it responsive to $r$ ), it is arguably a feature of the countries that pursued an inward-looking industrialization policy.

${ }^{13}$ Thus this country produces some brands of the differentiated good but these are non-traded. This we believe is also a feature of countries that followed an inward-looking industrialization policy.
} 


\section{Privatization}

In our framework the public sector maximizes

$$
\pi_{g}+(1-\psi) w\left(a_{L s} s+a_{L f}\right)
$$

where $0<\psi<1$. A higher value of $\psi$ implies less concern for labor spending. We model an increase in the degree of privatization as an increase in $\psi$ and explore its impact on product and factor prices, number of varieties, and finally welfare. For ease of exposition we will refer to an increase in $\psi$ as privatization (rather than an increase in the degree of privatization).

To facilitate the analysis, we express the equations as well as the comparative statics results in terms of proportionate changes (e.g. $\hat{x}=d \ln x=d x / x$ ).

Differentiation of (10), (11), and (12) gives, respectively,

$$
\begin{aligned}
& \theta_{L Y} \hat{w}+\theta_{K Y} \hat{r}=0, \\
& \theta_{L x} \hat{w}+\theta_{K x} \hat{r}=\hat{p},
\end{aligned}
$$

and

$$
\theta_{L F} \hat{w}+\theta_{K F} \hat{r}=\hat{p}+\hat{x},
$$

where $\theta_{i j}$ is the share of the factor $i$ in production of output $j$ as a proportion of marginal cost.

Recall that we assumed the capital intensities in the fixed and the variable components of the production are identical (i.e., $\theta_{i x}=\theta_{i F}, i=L, K$ ), which implies $\hat{x}=0$ (from (19) and (20)). Thus the scale of the private firm's production does not change with privatization, which implies that any change in aggregate production of the private brands is determined solely by entry-exit considerations. Solving for $\hat{w}$ and $\hat{r}$ from (18) and (19), in terms of $\hat{p}$, together with the factor-intensity ranking, yields the Stolper-Samuelson effects:

$$
\frac{\hat{w}}{\hat{p}}=-\frac{\theta_{K Y}}{\theta_{L Y}-\theta_{L x}}<0, \frac{\hat{r}}{\hat{p}}=\frac{\theta_{L Y}}{\theta_{L Y}-\theta_{L x}}>0 .
$$

Differentiating the pricing equation (13) of the PSE and then using (21) gives:

$$
\hat{q}=\theta_{L s} \hat{\psi}-\frac{\theta_{L s}-\theta_{L Y}}{\theta_{L Y}-\theta_{L x}} \hat{p}
$$

By lowering implicit subsidy, privatization directly raises the price of the public brand (q). However, there is also an indirect effect of privatization that operates through factor prices. The second term on the right-hand side of (22) captures this 
effect. In subsection 3.5 we show that the direct effect dominates: privatization leads to higher price of the PSE.

To understand how privatization impacts the PSE's output first we differentiate (7) and (9) which respectively yields:

$$
\begin{aligned}
& \hat{x}=-\sigma \hat{p}+(\sigma-1) \hat{P}+\hat{z} \\
& \hat{s}=-\sigma \hat{q}+(\sigma-1) \hat{P}+\hat{z}
\end{aligned}
$$

Using (22) - (24) and $\hat{x}=0$ we get:

$$
\hat{s}=\sigma\left(\frac{\theta_{L s}-\theta_{L x}}{\theta_{L Y}-\theta_{L x}}\right) \hat{p}-\sigma \theta_{L s} \hat{\psi}
$$

An increase in $\psi$ directly lowers the PSE's output. However, as equation (25) suggests that's not the only effect. Later, in subsection 3.5 we analyze these effects in details and show that the direct effect dominates. Privatization lowers the PSE's output.

Logarithmic differentiation of the factor-market clearing equations, followed by suitable substitution from (21) and (22) gives:

$$
\begin{gathered}
\gamma_{L Y} \hat{Y}+\left(\gamma_{L x}+\gamma_{L F}\right) \hat{n}+\left(\gamma_{L s}+\gamma_{L f}\right) \hat{s}=-\frac{\sum_{j} \gamma_{L j} \theta_{K j} \varepsilon_{j}}{\theta_{L Y}-\theta_{L x}} \hat{p}+\left[\frac{\gamma_{L s} \theta_{K s} \varepsilon_{s}}{\theta_{L Y}-\theta_{L x}}+\frac{\gamma_{L f} \theta_{K f} \varepsilon_{f}}{\theta_{L Y}-\theta_{L x}}\right] \hat{\psi} \\
\gamma_{K Y} \hat{Y}+\left(\gamma_{K x}+\gamma_{K F}\right) \hat{n}+\left(\gamma_{K s}+\gamma_{K f}\right) \hat{s}=\frac{\sum_{j} \gamma_{K j} \theta_{L j} \varepsilon_{j}}{\theta_{L Y}-\theta_{L x}} \hat{p}-\left[\frac{\gamma_{K s} \theta_{L s} \varepsilon_{s}}{\theta_{L Y}-\theta_{L x}}+\frac{\gamma_{K f} \theta_{L f} \varepsilon_{f}}{\theta_{L Y}-\theta_{L x}}\right] \hat{\psi},
\end{gathered}
$$

where $\gamma_{i j}$ is the physical share of factor $i$ in $j \in\{Y, x, F, s\}$ and $\varepsilon_{j}$ is the elasticity of substitution in production line $j$.

Further, differentiation of the price index (equation 4) and national income identity (equation 17) gives:

$$
\begin{aligned}
& \hat{P}=\frac{1}{1-\sigma} \beta_{1} \hat{n}+\beta_{1} \hat{p}+\beta_{2} \hat{q}, \\
& \hat{z}=\lambda_{w} \hat{w}+\lambda_{r} \hat{r}+\lambda_{t} \hat{x}^{*}+\lambda_{g} \hat{\pi}_{g}
\end{aligned}
$$

where $\beta_{1}, \beta_{2}$ and $\left(1-\beta_{1}-\beta_{2}\right)$ are the shares of domestic brands, the public brand, and foreign brands, respectively, in total expenditure on the differentiated good $(P X)$, and $\lambda_{w}, \lambda_{r}, \lambda_{g}, \lambda_{t}$ respectively denote the shares of (i) wage income ( $\left.w L\right)$, (ii) domestic capital income $(r K)$, (iii) PSE's profit $\left(\pi_{g}\right)$, and (iv) tariff revenue $\left(t^{*} p^{*} x^{*}\right)$, in national income.

In Appendix we show that differentiation of the goods-market clearing 
conditions in (7) - (9) with suitable substitutions from (21) - (23) in the resultant expressions yield

$$
A \hat{p}-\beta_{1} \hat{n}=-(\sigma-1) \beta_{2} \theta_{L s} \hat{\psi} .
$$

where $\mathrm{A}=(\sigma-1)\left(\beta_{1}+\beta_{2} \frac{\theta_{L Y}-\theta_{L s}}{\theta_{L Y}-\theta_{L x}}-\left(1-\lambda_{t}\right)\right)+\left(\frac{\lambda_{r} \theta_{L Y}-\lambda_{w} \theta_{K Y}}{\theta_{L Y}-\theta_{L x}}-\left(1-\lambda_{t}\right)\right)$ is strictly negative.

Observe that we have four equations --- (25), (26), (27) and (30) --- in four variables $\hat{Y}, \hat{n}, \hat{s}$ and $\hat{p}$. Now we are ready for the comparative statics. Hereafter, throughout the analysis, we focus on environment where the following conditions hold:

C1. Elasticity of substitution in all lines of production is low. In particular, we assume $\varepsilon_{\mathrm{j}} \approx 0$, where $\mathrm{j}=\mathrm{Y}, \mathrm{s}, \mathrm{f}$ and $\mathrm{F}$.

C2. The additional positive weight on labor spending in the PSE's objective function, i.e. $(1-\psi)$, is high or equivalently $\psi$ is low (recall, the PSE maximizes $\left.\pi_{g}+(1-\psi) w\left(a_{L s} s+a_{L f}\right)\right)$.

\subsection{Prices}

How does privatization affect the prices in our framework? Proposition 1 discusses the effect of privatization on price of the private brand and Proposition 2 examines the effect of privatization on factor prices: wages and returns to capital. The details of calculations are in Appendix.

Proposition 1: Privatization---modeled as an increase in $\psi$---raises the price of domestic private brands.

Proof: Solving (25) - (27) and (30) in Appendix we find that:

$$
\frac{\hat{p}}{\hat{\psi}}=-\frac{\theta_{L s}}{\Delta}\left[(\sigma-1) \beta_{2} \theta_{L s}\left[\gamma_{L Y}\left(\gamma_{K x}+\gamma_{K f}\right)-\gamma_{K Y}\left(\gamma_{L x}+\gamma_{L f}\right)\right]-\beta_{1} \sigma\left[\gamma_{L Y}\left(\gamma_{K s}+\gamma_{K f}\right)-\gamma_{K Y}\left(\gamma_{L s}+\gamma_{L f}\right)\right]\right]
$$

where 
$\Delta=A\left[\gamma_{L Y}\left(\gamma_{K x}+\gamma_{K F}\right)-\gamma_{K Y}\left(\gamma_{L x}+\gamma_{L F}\right)\right]+\beta_{1} \sigma \frac{\theta_{L s}-\theta_{L x}}{\theta_{L Y}-\theta_{L x}}\left[\gamma_{L Y}\left(\gamma_{K s}+\gamma_{K f}\right)-\gamma_{K Y}\left(\gamma_{L s}+\gamma_{L f}\right)\right]$

In Appendix, we show that $\mathrm{A}<0$ and $\Delta<0$. Since $x$ is least labor-intensive we have that (i) $\gamma_{L Y}\left(\gamma_{K x}+\gamma_{K f}\right)-\gamma_{K Y}\left(\gamma_{L x}+\gamma_{L f}\right)>0$. Furthermore, for low values of $\psi$, the public brand uses the most labor-intensive technique of production. Thus the following holds: (ii) $\gamma_{L Y}\left(\gamma_{K s}+\gamma_{K f}\right)-\gamma_{K Y}\left(\gamma_{L s}+\gamma_{L f}\right)<0$. The sign of $\Delta$, together with (i) and (ii) imply $\frac{\hat{p}}{\hat{\psi}}>0$.

QED

That privatization leads to higher prices also arise in a partial equilibrium framework. As public firms become more profit-oriented they cut back their output which in turn leads to higher prices. See, for example, Anderson et al (1997). Since the same result hold here, it might seem that general equilibrium concerns or more specifically factor-market considerations do not add much. However, note that the result remains unaltered only if factor-intensity rankings are right! For example, if the differentiated goods sector is labor-intensive compared to the homogenous goods sector and the PSE uses the most capital-intensive technique then privatization might lead to lower prices.

Proposition 2: Privatization leads to lower wages and higher returns to capital.

Proof: By Proposition 1, (i) $\frac{\hat{p}}{\hat{\psi}}>0$. From (21) we have (ii) $\frac{\hat{w}}{\hat{p}}<0$, and (iii) $\frac{\hat{r}}{\hat{p}}>0$. Together (i) and (ii) imply privatization lowers wages (i.e., $\frac{\hat{w}}{\hat{\psi}}<0$ ) while (i) and (iii) imply that privatization raises the returns to capital (i.e., $\frac{\hat{r}}{\hat{\psi}}>0$ ).

QED

An increase in $\psi$ which effectively acts as a reduction in wage subsidy to the PSE results in lower demand for labor in the PSE. Overall, this leads to an excess supply of labor since for low values of $\psi$, the PSE uses the most labor-intensive technique. Excess supply of labor in turn leads to lower wages. Opposite is true for returns to capital. 


\subsection{Number of varieties}

Ours is a small open economy model, and, accordingly, the number of foreign brands is exogenously given (see Venables, 1982 and Sen et al., 1997 for a rationalization of the assumption). Hence, to determine the effects of privatization on the number of varieties available to consumers, it is sufficient to examine the effect of privatization on the number of domestic brands produced.

Proposition 3: Privatization reduces the number of domestic varieties.

Proof: Solving (25) - (27) and (30) in Appendix we get:

$$
\frac{\hat{n}}{\hat{\psi}}=\frac{\sigma \theta_{L s}\left(\gamma_{L Y}\left(\gamma_{K s}+\gamma_{K f}\right)-\gamma_{K Y}\left(\gamma_{L s}+\gamma_{L f}\right)\right)}{\Delta}\left[A+(\sigma-1) \beta_{2} \frac{\theta_{L s}-\theta_{L x}}{\theta_{L Y}-\theta_{L x}}\right]
$$

We have already established in Appendix that $\Delta<0$. Furthermore, the assumed factor-intensity rankings imply $\gamma_{L Y}\left(\gamma_{K s}+\gamma_{K f}\right)-\gamma_{K Y}\left(\gamma_{L s}+\gamma_{L f}\right)<0$. Thus

$$
\operatorname{sign} \frac{\hat{n}}{\hat{s}}=\operatorname{sign}\left[A+(\sigma-1) \beta_{2} \frac{\theta_{L s}-\theta_{L x}}{\theta_{L Y}-\theta_{L x}}\right]
$$

We find that $A+(\sigma-1) \beta_{2} \frac{\theta_{L s}-\theta_{L x}}{\theta_{L Y}-\theta_{L x}}=-\left[(\sigma-1)\left(1-\lambda_{t}-\beta_{1}-\beta_{2}\right)+\frac{\lambda_{w}-\theta_{L x}}{\theta_{L Y}-\theta_{L x}}\right]<0$.

Thus $\frac{\hat{n}}{\hat{\psi}}<0$.

QED

There are two effects at work here. As argued previously --- see the discussion after Proposition 2 --- an increase in privatization leads to excess supply of labor and excess demand for capital. This implies that at given prices the capital-intensive sector producing private brands will contract. Thus, at given prices, privatization induces exit of private domestic firms. This channel arises due to general equilibrium considerations where factors are reallocated even if prices are fixed. However, prices are not fixed. Proposition 1 showed that privatization raises the price of the domestic private brand which encourages entry into the differentiated goods sector, suggesting that the differentiated goods sector would expand following privatization. For low elasticities of substitution (in production), the effect operating through the price channel is weak, which in turn gives Proposition 3.

Anderson et al. (1997) show that privatization of a public firm - modeled as a 
switch from welfare maximization to profit maximization as the objective functionincreases the number of brands in the long run. Privatization raises price which induce entry. In contrast, we find that when private and public firms use different technologies (as they often do in reality), privatization can lead to the exit of private firms from the differentiated goods sector. In addition to increased product prices and lower wages, now there is one more source of welfare loss from privatization - fewer domestic varieties. $^{14}$

Note that both conditions $\mathrm{C} 1$ and $\mathrm{C} 2$ - large weight on labor spending and low elasticity of substitution in production --- are crucial for Proposition 3. If the weight on labor spending is very small, the public variety is almost as capital-intensive as the domestic private ones. In such cases, a decline in public brand production does not necessarily lead to exit of private brands. If the elasticities of substitution are high in production, entry induced by higher price of private brand might lead to a higher number of domestic varieties following privatization.

\subsection{Trade and tariff revenues}

Does privatization promote trade or hinder trade? According to our framework, privatization raises the price of domestic brands which makes foreign brands more attractive vis-à-vis the domestic brands and consequently imports increase following privatization. Thus privatization and trade flows are complementary in our framework. Since tariff rate is exogenously set in our model, tariff revenues also increase following privatization.

\section{Proposition 4: Privatization leads to higher imports and consequently higher tariff} revenues.

Proof: Substituting $\hat{x}=0$ in (23) and rearranging gives the following equality: $\hat{\sigma p}=(\sigma-1) \hat{P}+\hat{z}$. Differentiating (8) gives and using the equality we get

$$
\hat{x}^{*}=(\sigma-1) \hat{P}+\hat{z}
$$

\footnotetext{
${ }^{14}$ A reduction in the number of brands from the free entry level can improve welfare by economizing on entry costs and lowering the average cost (if there are economies of scale). In a homogenous product oligopoly, Mankiw and Whinston (1986) and Suzumura and Kiyono (1987) have shown that entry regulation can indeed improve welfare. However, under Dixit-Stiglitz preferences (capturing love for variety) a reduction in the number of brands lowers welfare.
} 
which imply $\frac{\hat{x}^{*}}{\hat{\psi}}=\sigma \frac{\hat{p}}{\hat{\psi}}>0$. Since $t$ is fixed, $t x^{*}$ increases with privatization as well.

QED

In a recent work on mixed oligopolies, Mukherjee and Suetrong (2009) showed that privatization encourages foreign direct investment. Our work offers a complementary message. Privatization leads to an increase in trade flows. In particular, more foreign brands are imported as the domestic brands become more expensive with privatization.

\subsection{Public sector enterprise}

To understand the effect of privatization on the PSE's output, rewrite (25) as follows:

$$
\hat{s}=-\sigma \theta_{L s} \hat{\psi}+\sigma\left(\frac{\theta_{L s}-\theta_{L Y}}{\theta_{L Y}-\theta_{L x}}\right) \hat{p}+\sigma \hat{p}
$$

Privatization, acting as a reduction in implicit wage subsidy, increases marginal cost and reduces PSE's output. The first term on the right-hand side, $-\sigma \theta_{L s} \hat{\psi}$, captures this direct effect. In our general equilibrium framework there is an additional effect on the cost side: privatization lower wages and raises return to capital (Proposition 2). As long as PSE's production is the most labor-intensive one, this effect partially offsets the higher cost (due to lower implicit wage subsidy). The second term on the right-hand side, $\sigma\left(\frac{\theta_{L s}-\theta_{L Y}}{\theta_{L Y}-\theta_{L x}}\right) \hat{p}$, captures this positive effect. Finally, the third term, $\hat{\sigma p}$, captures the increased demand for the PSE's brand (at a given $q$ ) as the private brands become more expensive following privatization. We find that the direct effect (i.e., the first one) dominates leading to contraction of the PSE.

Proposition 5: Privatization lowers output and raises price of the public brand.

Proof: Substituting the expression for $\frac{\hat{p}}{\hat{\psi}}$ from the proof of Proposition 1 in (25) and rearranging yields: 


$$
\frac{\hat{s}}{\hat{\psi}}=-\frac{\sigma \theta_{L s}}{\Delta}\left[A+(\sigma-1) \beta_{2} \frac{\theta_{L s}-\theta_{L x}}{\theta_{L Y}-\theta_{L x}}\right]
$$

From the proof of Proposition 3 we know that $A+(\sigma-1) \beta_{2} \frac{\theta_{L s}-\theta_{L x}}{\theta_{L Y}-\theta_{L x}}<0$. Moroever, as we have established before, $\Delta<0$. Hence $\frac{\hat{s}}{\hat{\psi}}<0$.

Using (23), (25) and $\hat{x}=0$ we get:

$$
\frac{\hat{q}}{\hat{\psi}}=-\frac{1}{\sigma} \frac{\hat{s}}{\hat{\psi}}+\frac{\hat{p}}{\hat{\psi}}
$$

The result follows from noting that $\frac{\hat{s}}{\hat{\psi}}<0$ and $\frac{\hat{p}}{\hat{\psi}}>0$.

Proposition 5 confirms what one expects: privatization cuts back the PSE's output and raises the price of the public brand. However, as we show above, there are subtle general equilibrium mechanisms at work which operate through factor markets.

Finally, we turn to the PSE's profit. According to its proponents, a significant benefit of privatization is that it cuts down public sector losses. Anderson et. al (1997) showed that in the long run with free entry of firms privatization improves welfare only if the public firm makes losses. As the PSEs are not required to make nonnegative profits, it is often assumed that losses made by the PSE are covered by lumpsum taxes on consumers. On the other hand, several authors impose a nonnegativity constraint on PSE's profit arguing that taxes are distortionary and probably more so in developing countries (see, for example, Saha and Sensarma, 2004). Whether PSE makes profit or not is not crucial for our results. Following privatization, the PSE's operating profit increases as q increases and s declines.

\subsection{Closed Economy versus Open Economy ${ }^{15}$}

Note that while we conduct our analysis in an open economy setup, most of our results hold in the closed economy set up as well. For example, the effect of privatization on (i) the prices of the domestic private brands (Proposition 1), (ii) factor prices (Proposition 2) and (iii) the number of domestic varieties (Proposition 3) does not rely on open economy features of the model. In that sense closed economy setup

\footnotetext{
${ }^{15}$ We wish to thank an anonymous referee for suggesting us to comment on this issue.
} 
in our context is a special case of open economy set up, where the share of imports in domestic consumption bundle and the share of tariff revenues in national income is zero. Despite this, we focus on an open economy model since some of the issues considered in conjunction with privatization in the policy circles, e.g., trade liberalization, capital inflows, requires open economy setting. We examine the possible complementarities between these policies in section 5 .

\section{Political Support for Privatization}

Support for any reform comes from those who stand to gain from the reforms. Our analysis suggests that the capitalists - both domestic and foreign - benefit from higher returns to capital following privatization (see Proposition 2). Thus capitalists are likely to support privatization unless the loss from the reduction in the number of varieties is large.

Since imports increase with privatization, foreign firms will support privatization as well. In addition, the revenue-constrained governments - a feature that we abstract from but which is often the case in developing countries - are likely to be supportive of privatization as it raises tariff revenues. ${ }^{16}$ If foreign firms are influential in domestic policies or if the political scenario is such that governments can ignore the wishes of the majority (i.e., workers in this case), then, once again, privatization can be successfully implemented.

However, in several countries undertaking or willing to undertake privatization, workers, due to their sheer numbers, play an important role. This suggests that at least in democracies with a significant involvement of PSEs (e.g., India, Turkey), a precondition for privatization to be politically viable is that the workers are not worse off. $^{17}$

Remarks: Although we focus on the welfare effects of privatization on workers,

${ }^{16}$ There is a direct increase in government revenues from the sale of PSEs, which we do not focus on here. Our analysis shows that there is also an indirect channel through which the government's revenues could increase - through increased imports subject to tariffs.

${ }^{17}$ Although we focus on the welfare of workers alone, the fact that these workers are considered identical places our model somewhere between a political economy model (with differential endowments among individuals) and the canonical welfare maximizing social planner who puts equal weights on utilities of all individuals. See Dutt and Mitra (2002) for a simple political economy model in an open economy context. Baland and Francois (2005) look at privatization in the presence of a commons and find that privatization may increase efficiency but reduce welfare. 
except when we consider factor returns, the interests of capitalists and workers are aligned. For example, both capitalists and workers are adversely affected by an increase in domestic brand prices and a possible decline in the number of varieties consumed. Indeed, if the workers are better off with privatization, capitalists are also better off, although the reverse is not true.

Second, one might ask why improvement in workers' welfare is considered in isolation. After all, if privatization improves welfare, then surely some transfers can be arranged so that the workers are as well off as without privatization. This point requires clarification. Note that since returns to capital increases with privatization, national income can increase with privatization, if the share of rental income in national income is large. However, an increase in national income does not necessarily translate to increase in welfare as price index increases with privatization as well. Even if the welfare gains from an increase in national income outweighs the welfare loss from a reduction in the number of varieties, it is not clear whether redistribution/transfers can be implemented. In fact, it is precisely because those transfers are highly costly and distortionary that the governments in these countries resort to direct production of manufacturing output in the first place.

Third, the standard political economy models assume that each individual is endowed with one unit of labor and differential amounts of capital. Political support depends on whether the median voter's welfare improves with privatization. Here we assume that workers are identical and have no capital. While it might seem extreme, the assumption is not far from reality in the developing economies - the median individual in these countries has little or no capital.

Now we turn to the effect of privatization on workers' welfare. Let $V_{w}$ denote the indirect utility of the representative worker. For simplicity, we assume now that the tariff revenues are returned to the workers while taxes (if any) are paid by the capitalists.

Proposition 6: If the share of tariff revenue in workers' income is low, privatization reduces workers' welfare.

Proof: The utility maximization exercise in (1), together with the fact that the workers' income consists of wages and tariff revenues, gives

$$
V_{w}=\alpha^{\alpha}(1-\alpha)^{1-\alpha}\left(w+\frac{t^{*} p^{*} x^{*}}{\bar{L}}\right) P^{-\alpha} .
$$


Differentiating logarithmically and rearranging yields

$$
\frac{\hat{V}_{w}}{\hat{\psi}}=\mu \frac{\hat{w}}{\hat{\psi}}+(1-\mu) \frac{\hat{x}^{*}}{\hat{\psi}}-\alpha \beta_{1} \frac{\hat{p}}{\hat{\psi}}-\alpha \beta_{2} \frac{\hat{q}}{\hat{\psi}}+\frac{\alpha \beta_{1}}{\sigma-1} \frac{\hat{n}}{\hat{\psi}},
$$

where $\mu$ denotes the share of wages in a worker's income.

By Propositions 1 and 5 respectively, $\frac{\hat{p}}{\hat{\psi}}>0$ and $\frac{\hat{q}}{\hat{\psi}}>0$. Proposition 2 says that privatization lowers wages, i.e., $\frac{\hat{\psi}}{\hat{\psi}}<0$. In addition, from Proposition 3 we know that privatization lowers the number of varieties (i.e., $\frac{\hat{n}}{\hat{\psi}}<0$ ). From (33) it follows that if there are no tariff revenues $(\mu=1), \frac{\hat{V}_{w}}{\hat{\psi}}>0$. Privatization benefits workers only through increased tariff revenues resulting from higher imports $\left(\frac{\hat{x}^{*}}{\hat{\psi}}<0\right)$. If the share of tariff revenue in workers' income (i.e., $1-\mu$ ) is small, then the conclusion obtained with $\mu=1$ continues to hold. That is, $\frac{\hat{V}_{w}}{\hat{\psi}}>0$.

QED

Though the wages are lower and the prices (of domestic brands) are higher with privatization, the number of varieties might be more or less depending on the elasticities of substitution in production - see the discussion in section 3.2. The low elasticities (e.g., Leontief technology) ensure that the number of varieties decline with privatization, which adds to the welfare loss arising from lower wages and higher prices. Even if the elasticity of substitutions are large and consequently the number of varieties increases following privatization, the workers' welfare will still generally be lower with privatization due to lower wages and higher prices. However, for low values of $\sigma$ (the elasticity of substitution between the various brands), which implies a very strong love for variety, it is possible that the welfare gains from the increased number of varieties outweigh the welfare losses from the other sources.

Remark: Following the literature on small open economy models of monopolistic competition, we have assumed that the number of imported varieties is exogenously given. With an endogenous number of foreign varieties, privatization can lead to an increase in the number of foreign brands since domestic brands become more 
expensive with privatization. This suggests a reduction in the overall number of varieties and consequently the welfare loss is less when the number of imported varieties is endogenously determined. Although this partially offsets the negative impact of privatization, it is unlikely to outweigh the welfare loss arising from a reduction in wages.

\section{Complementary Reforms}

Since the capitalists and the foreign firms gain from privatization, complementary reforms are not necessary in order to implement privatization if these groups are influential in the policy making. However, if workers' welfare is the central concern, then privatization alone will not be politically viable. Does that mean privatization, as a goal, is unattainable in democratic developing economies? The answer is no according to the analysis in this section. Although privatization, pursued alone, can reduce workers' welfare, there are complementary policies which, if undertaken along with privatization, can offset the welfare loss. Given that ours is a tariff-ridden open economy, we consider two policy interventions, which are absent in a closed economy model—namely, an increase in foreign investment and a reduction in the tariff rate.

\subsection{Foreign Investment}

Recall from section 4 that the workers are better off with privatization if and only if the following holds (see equation 33):

$$
\frac{\hat{V}_{w}}{\hat{\psi}} \geq 0 \Leftrightarrow \mu \frac{\hat{w}}{\hat{\psi}}+(1-\mu) \frac{\hat{x}^{*}}{\hat{\psi}}-\alpha \beta_{1} \frac{\hat{p}}{\hat{\psi}}-\alpha \beta_{2} \frac{\hat{q}}{\hat{\psi}}+\frac{\alpha \beta_{1}}{\sigma-1} \frac{\hat{n}}{\hat{\psi}} \geq 0
$$

which upon simplification yields

$$
\frac{\hat{V}_{w}}{\hat{\psi}} \geq 0 \Leftrightarrow-\left[\frac{\mu \theta_{K Y}}{\theta_{L Y}-\theta_{L x}}+\alpha \beta_{1}-(1-\mu) \sigma-\alpha \beta_{2} \frac{\theta_{L s}-\theta_{L Y}}{\theta_{L Y}-\theta_{L x}}\right] \frac{\hat{p}}{\hat{\psi}}+\frac{\alpha \beta_{1}}{\sigma-1} \frac{\hat{n}}{\hat{\psi}}-\alpha \beta_{2} \theta_{L s} \geq 0 .
$$

Amending (27) to incorporate proportional changes in foreign capital and then solving (25) - (27) and (30) gives (see Appendix) 


$$
\begin{aligned}
& \frac{\hat{n}}{\hat{\psi}}=\left(\frac{\hat{n}}{\hat{\psi}}\right)_{\text {prev }}+\frac{A f \gamma_{L Y}}{\Delta} \frac{\hat{\bar{K}}_{f}}{\hat{\psi}}, \\
& \frac{\hat{p}}{\hat{\psi}}=\left(\frac{\hat{p}}{\hat{\psi}}\right)_{\text {prev }}+\frac{\beta_{1} f \gamma_{L Y}}{\Delta} \frac{\hat{\bar{K}}_{f}}{\hat{\psi}},
\end{aligned}
$$

where $f$ denotes the foreign share in the total capital employed in the economy, $\Delta<0$ (as mentioned earlier), $\left(\frac{\hat{n}}{\hat{\psi}}\right)_{\text {prev }}$ and $\left(\frac{\hat{p}}{\hat{\psi}}\right)_{\text {prev }}$ denote, respectively, the effect of privatization on the number of varieties and the price, in the absence of other policy interventions - these are given by (32) and (31) in section 3.

Substituting (35a) and (35b) in (34) and defining

$$
\left(\frac{\hat{V}_{w}}{\hat{\psi}}\right)_{\text {prev }}=-\left[\frac{\mu \theta_{K Y}}{\theta_{L Y}-\theta_{L x}}+\alpha \beta_{1}-(1-\mu) \sigma-\alpha \beta_{2} \frac{\theta_{L s}-\theta_{L Y}}{\theta_{L Y}-\theta_{L x}}\right]\left(\frac{\hat{p}}{\hat{\psi}}\right)_{\text {prev }}+\frac{\alpha \beta_{1}}{\sigma-1}\left(\frac{\hat{n}}{\hat{\psi}}\right)_{\text {prev }}-\alpha \beta_{2} \theta_{L s}
$$

we find that

$$
\frac{\hat{V}_{w}}{\hat{\psi}} \geq 0 \Leftrightarrow\left(\frac{\hat{V}_{w}}{\hat{\psi}}\right)_{p r e v}-\left[\frac{\mu \theta_{K Y}}{\theta_{L Y}-\theta_{L x}}+\alpha \beta_{1}-(1-\mu) \sigma-\alpha \beta_{2} \frac{\theta_{L s}-\theta_{L Y}}{\theta_{L Y}-\theta_{L x}}\right] \frac{\beta_{1} f \gamma_{L Y}}{\Delta} \frac{\hat{\bar{K}}_{f}}{\hat{\psi}}+\frac{\alpha \beta_{1}}{\sigma-1} \frac{A f \gamma_{L Y}}{\Delta} \frac{\hat{\bar{K}}_{f}}{\hat{\psi}} \geq 0 .
$$

Consider a scenario where privatization reduces worker's welfare, i.e., $\left(\frac{\hat{V}_{w}}{\hat{\psi}}\right)_{\text {prev }}<0$. Assume that $\mu$ is large. That is, the share of wages in a worker's overall income is large. It can be shown that for sufficiently large $\mu$, the term $\left[\frac{\mu \theta_{K Y}}{\theta_{L Y}-\theta_{L x}}+\alpha \beta_{1}-(1-\mu) \sigma-\alpha \beta_{2} \frac{\theta_{L s}-\theta_{L Y}}{\theta_{L Y}-\theta_{L x}}\right]$ is strictly positive. Then from (35a) and (35b) respectively it follows that if foreign investment is increased along with privatization, the number of domestic varieties increases and prices decline, both of which reduce the welfare losses that arise when privatization alone is implemented. Indeed, given $A$ and $\Delta$ are negative, (36) implies that an increase in foreign investment 
is necessary with privatization (i.e., $\frac{\hat{\bar{K}}_{f}}{\hat{\psi}}<0$ ) for an improvement in workers' welfare. The precise magnitude of the foreign capital $\left(\frac{\hat{\bar{K}}_{f}}{\hat{\psi}}\right)$ required to neutralize the welfare loss arising from privatization alone is determined by setting $\frac{\hat{V}_{w}}{\hat{\psi}}=0$.

Proposition 7: Privatization, combined with suitable increases in foreign investment, increases workers' welfare.

Proof: Follows from the discussion above.

To understand Proposition 7, note that an increase in foreign investment has two welfare-improving effects. First, it leads to an increase in the number of domestic private brands - the capital-intensive sector in our framework. Second, an increased supply of foreign capital leads to higher wages. Since wages and brand prices are negatively related — via the Stolper-Samuelson effect—prices are also lower. Both these effects raise welfare.

It might seem that an increase in foreign capital is unambiguously welfare improving, with or without privatization. However, that is not necessarily the case. In a small open economy with perfect competition, several authors (including Johnson, 1967 and Bhagwati, 1968) have shown that an inflow of foreign capital could immiserize the recipient economy in the presence of tariffs in a large number of scenarios. Indeed, Brecher and Diaz-Alejandro (1977) showed that an inflow of foreign capital is necessarily immiserizing, if the import-competing sector is capital intensive and foreign capital income is repatriated in full. ${ }^{18}$ The import-competing differentiated goods sector is indeed capital intensive (ignoring the public firm) in our framework and focusing on workers' welfare alone makes our model akin to a set up where the capital income accrues entirely to foreigners. However, in the presence of imperfect competition in the import-competing sector - which is true for our framework - the immiserization is unlikely to hold.

${ }^{18}$ Grinols (1991) provides an example in a Harris-Todaro framework where immiserization does not occur. 


\subsection{Trade Liberalization}

Now consider combining trade liberalization with privatization. Note that in a model such as ours, trade liberalization by itself is welfare reducing since it causes an exit from the domestic differentiated goods sector (see, e.g., Venables, 1982). Incorporating trade liberalization (i.e., a reduction in tariff rate $t$ ) in the presence of privatization, however, improves workers' welfare only if the following holds:

$$
\begin{aligned}
\frac{\hat{V}_{w}}{\hat{\psi}} \geq 0 \Leftrightarrow & -\left[\frac{\mu \theta_{K Y}}{\theta_{L Y}-\theta_{L x}}+\alpha \beta_{1}-(1-\mu) \sigma-\alpha \beta_{2} \frac{\theta_{L s}-\theta_{L Y}}{\theta_{L Y}-\theta_{L x}}\right] \frac{\hat{p}}{\hat{\psi}} \\
& +\frac{\alpha \beta_{1}}{\sigma-1} \frac{\hat{n}}{\hat{\psi}}-\alpha \beta_{2} \theta_{L s}-\left(\alpha\left(1-\beta_{1}-\beta_{2}\right)-(1-\mu)\left(1+\frac{1}{t}\right)\right) \frac{\hat{T}}{\hat{\psi}} \leq 0
\end{aligned}
$$

where $t>0, T=1+t$, and

$$
\begin{aligned}
& \frac{\hat{n}}{\hat{\psi}}=\left(\frac{\hat{n}}{\hat{\psi}}\right)_{\text {prev }}+\frac{C \sigma\left(\theta_{L s}-\theta_{L x}\right)\left(\gamma_{L Y}\left(\gamma_{K s}+\gamma_{K f}\right)-\gamma_{K Y}\left(\gamma_{L s}+\gamma_{L f}\right)\right)}{\Delta\left(\theta_{L Y}-\theta_{L x}\right)} \frac{\hat{T}}{\hat{\psi}}, \\
& \frac{\hat{p}}{\hat{\psi}}=\left(\frac{\hat{p}}{\hat{\psi}}\right)_{\text {prev }}-\frac{C\left[\gamma_{L Y}\left(\gamma_{K x}+\gamma_{K F}\right)-\gamma_{K Y}\left(\gamma_{L x}+\gamma_{L F}\right)\right]}{\Delta} \frac{\hat{T}}{\hat{\psi}} .
\end{aligned}
$$

In Appendix, we derive the expression for $\mathrm{C}$ and show that (i) $\mathrm{C}>0$. We have already shown that (ii) $\Delta<0$. The assumed factor intensity rankings imply that (iii) $\theta_{L Y}-\theta_{L x}>0$, (iv) $\theta_{L s}-\theta_{L x}<0$, (v) $\gamma_{L Y}\left(\gamma_{K x}+\gamma_{K F}\right)-\gamma_{K Y}\left(\gamma_{L x}+\gamma_{L F}\right)>0$, (vi) $\gamma_{L Y}\left(\gamma_{K s}+\gamma_{K f}\right)-\gamma_{K Y}\left(\gamma_{L s}+\gamma_{L f}\right)<0$. Together, (i) - (vi) imply that

$$
\frac{\hat{n}}{\hat{\psi}}<\left(\frac{\hat{n}}{\hat{\psi}}\right)_{\text {prev }}, \frac{\hat{p}}{\hat{\psi}}<\left(\frac{\hat{p}}{\hat{\psi}}\right)_{\text {prev }} .
$$

That is if trade liberalization is pursued along with privatization (i.e., $\frac{\hat{T}}{\hat{\psi}}<0$ ), number of domestic varieties will decline even further while the price of the domestic private brands will decline. That trade liberalization leads to fewer domestic private brands might be surprising. However, note that the small open economy exports homogenous goods in our framework. With trade liberalization, the exportable sector producing the homogenous good expands whereas the import-competing sector producing differentiated brands contracts, and accordingly the number of domestic private brands decline. The reduction in the number of private brands, $n$, raises the price index and lowers welfare. 
How does privatization impact total welfare when it is pursued along with trade liberalization? To answer that first we substitute (38a) and (38b) in (37). Then, defining $\left(\frac{\hat{V}_{w}}{\hat{\psi}}\right)_{\text {prev }}$ as in subsection 5.1, we find that

$$
\begin{aligned}
& \frac{\hat{V}_{w}}{\hat{\psi}} \geq 0 \Leftrightarrow\left(\frac{\hat{V}_{w}}{\hat{\psi}}\right)_{\text {prev }}-\left(\alpha\left(1-\beta_{1}-\beta_{2}\right)-(1-\mu)\left(1+\frac{1}{t}\right)\right) \frac{\hat{T}}{\hat{\psi}} \\
& +\left(\frac{\mu \theta_{K Y}}{\theta_{L Y}-\theta_{L x}}+\alpha \beta_{1}-(1-\mu) \sigma-\alpha \beta_{2} \frac{\theta_{L s}-\theta_{L Y}}{\theta_{L Y}-\theta_{L x}}\right)\left[\frac{\hat{p}}{\hat{\psi}}-\left(\frac{\hat{p}}{\hat{\psi}}\right)_{\text {prev }}\right] \\
& +\frac{\alpha \beta_{1}}{\sigma-1}\left[\frac{\hat{n}}{\hat{\psi}}-\left(\frac{\hat{n}}{\hat{\psi}}\right)_{\text {prev }}\right] \geq 0 .
\end{aligned}
$$

The second term on the right-hand side of (39) captures the direct beneficial effect of a reduction in tariff rates. A reduction in tariff rates directly benefits the consumers by lowering the price index. However, tariff reductions also lower tariff revenues. The former beneficial effect (i.e., lower prices) dominates the latter as long as $\alpha\left(1-\beta_{1}-\beta_{2}\right)-(1-\mu)(1+1 / t)>0$ - which holds if the share of rebated tariff revenue in a worker's overall income is small (i.e., $\mu$ is large). We had assumed this to be the case.

The third term on the RHS of (39) captures an additional benefit from trade liberalization which works through lower prices. Note that the lower prices of private brands not only benefit consumers directly, but also through an increase in wages.

To summarize, though there are gains from trade liberalization due to higher wages and lower prices of foreign and domestic private brands, the number of varieties is reduced with trade liberalization. The magnitude of the adverse welfare effect of trade liberalization is small if brands are close substitutes ( $\sigma$ large). This implies the following Proposition.

Proposition 8: Privatization combined with trade liberalization increases workers' welfare provided the brands are not too differentiated (i.e., $\sigma$ is not close to unity). Proof: Follows from the discussion above.

These two propositions, i.e., Propositions 7 and 8, suggest an otherwise unpopular privatization might be politically viable if governments can undertake 
reforms in other arenas as well—in our case, trade and capital accounts.

\section{Conclusion}

Prompted by poor performance and widespread inefficiencies, governments in several developing countries have attempted to withdraw from the manufacturing sector, in which it used to have a significant share both in terms of output and employment. What are the welfare consequences of such a retreat? We attempted to address this question by embedding public sector production - characterized by laborintensive techniques and a lack of market discipline (these firms continue to produce even if profits are negative) — in a general equilibrium model with imperfect competition. Although there is a small body of work incorporating the government provision of public goods in the trade literature, direct government production does not seem to have received much attention.

Our findings suggest that privatization may have several benefits. It reduces losses of the PSEs, raises the returns to capital, and increases the tariff revenue - all of which improve welfare. However, due to the use of labor-intensive techniques, a shrinking of the public sector might create unemployment or in a full-employment model like ours, lower wages. More surprisingly, we find that if elasticities of substitution are low in production, private brands producers, rather than filling up the void created through the contraction of the public sector, might actually exit. Fewer brands together with lower wages reduce the welfare of workers. This suggests that pursuing privatization alone might be politically costly.

According to our model, to do it right-i.e., to privatize without immiserizing the workers - requires complementary reforms. In particular, the government needs to provide suitable incentives and an environment to attract foreign investment into the country. This stands in sharp contrast to findings from perfectly competitive trade models where capital inflow in a tariff-distorted economy, with a capital-intensive importable sector, reduces welfare. Trade liberalization (also welfare-reducing by itself in presence of imperfect competition), if pursued along with privatization improves workers' welfare only if there is not much differentiation-which is true if the sector produces relatively basic manufacturing goods. 


\section{Appendix}

\section{Derivation of (30)}

Differentiating (7), (8), and (9) respectively yield:

$$
\begin{aligned}
& 0=-\sigma \hat{p}+(\sigma-1) \hat{P}+\hat{z}, \\
& \hat{x}^{*}=(\sigma-1) \hat{P}+\hat{z}, \\
& \hat{s}=-\sigma \hat{q}+(\sigma-1) \hat{P}+\hat{z} .
\end{aligned}
$$

Subtracting (A1) from (A3) gives

$$
\hat{s}=\sigma(\hat{p}-\hat{q}), \text { i.e. } \hat{q}=\hat{p}-\frac{\hat{s}}{\sigma},
$$

and subtracting (A1) from (A2) yields

$$
\hat{x}^{*}=\hat{\sigma p} \text {. }
$$

Assume $\lambda_{g} \approx 0$. Then using (21), (22) and (A5) we can rewrite (27) and (26) as follows:

$$
\begin{gathered}
\hat{z}=\left(\frac{\lambda_{r} \theta_{L Y}-\lambda_{w} \theta_{K Y}}{\theta_{L Y}-\theta_{L x}}+\lambda_{t} \sigma\right) \hat{p} \\
(\sigma-1) \hat{P}=-\beta_{1} \hat{n}+(\sigma-1) \beta_{1} \hat{p}+(\sigma-1) \beta_{2} \frac{\theta_{L Y}-\theta_{L s}}{\theta_{L Y}-\theta_{L x}} \hat{p}+(\sigma-1) \beta_{2} \theta_{L s} \hat{\psi}
\end{gathered}
$$

Adding these equations and using

$$
\hat{x}^{*}=\hat{z}+(\sigma-1) \hat{P}=\hat{\sigma p}
$$

gives:

$-\beta_{1} \hat{n}+\left[(\sigma-1)\left(\beta_{1}+\beta_{2} \frac{\theta_{L Y}-\theta_{L s}}{\theta_{L Y}-\theta_{L x}}-\left(1-\lambda_{t}\right)\right)+\left(\frac{\lambda_{r} \theta_{L Y}-\lambda_{w} \theta_{K Y}}{\theta_{L Y}-\theta_{L x}}-\left(1-\lambda_{t}\right)\right)\right] \hat{p}=-(\sigma-1) \beta_{2} \theta_{L s} \hat{\psi}$

Equation (28) in the text follows once we define

$$
\mathrm{A}=(\sigma-1)\left(\beta_{1}+\beta_{2} \frac{\theta_{L Y}-\theta_{L s}}{\theta_{L Y}-\theta_{L x}}-\left(1-\lambda_{t}\right)\right)+\left(\frac{\lambda_{r} \theta_{L Y}-\lambda_{w} \theta_{K Y}}{\theta_{L Y}-\theta_{L x}}-\left(1-\lambda_{t}\right)\right)
$$




\section{Sign of $A$}

Now consider the sign of $A$. The maximum value of $\beta_{1}+\beta_{2} \frac{\theta_{L Y}-\theta_{L s}}{\theta_{L Y}-\theta_{L x}}-\left(1-\lambda_{t}\right)$ is $\beta_{1}+\beta_{2}+\lambda_{t}-1=-\left(1-\beta_{1}-\beta_{2}-\lambda_{t}\right)=-\left(\frac{n^{*} p^{*}(1+t) x^{*}}{\alpha z}-\frac{t^{*} p^{*} x^{*}}{z}\right)=-\frac{n^{*} p^{*} x^{*}}{\alpha z}(1+t(1-\alpha))<0$

Similarly using $\lambda_{w}+\lambda_{r} \approx 1-\lambda_{t}\left(\right.$ since $\left.\lambda_{g} \approx 0\right)$ it can be shown that

$$
\frac{\lambda_{r} \theta_{L Y}-\lambda_{w} \theta_{K Y}}{\theta_{L Y}-\theta_{L x}}-\left(1-\lambda_{t}\right)=-\frac{\lambda_{w}-\left(1-\lambda_{t}\right) \theta_{L x}}{\theta_{L Y}-\theta_{L x}}=-\frac{\lambda_{w}\left(\theta_{L x}+\theta_{K x}\right)-\left(\lambda_{w}+\lambda_{r}\right) \theta_{L x}}{\theta_{L Y}-\theta_{L x}}<0
$$

From (A8) and (A9) it follows that A, as defined in (A7), is negative.

\section{Derivations of (31) and (32)}

Substituting (25) in (26) and (27) and assuming $\varepsilon_{\mathrm{j}} \approx 0$, equations (26), (27) and (30) can be written in the matrix form as follows:

$$
\left[\begin{array}{ccc}
\gamma_{L Y} & \gamma_{L x}+\gamma_{L F} & \sigma\left(\gamma_{L s}+\gamma_{L f}\right)\left(\frac{\theta_{L s}-\theta_{L x}}{\theta_{L Y}-\theta_{L x}}\right) \\
\gamma_{K Y} & \gamma_{K x}+\gamma_{K F} & \sigma\left(\gamma_{K s}+\gamma_{K f}\right)\left(\frac{\theta_{L s}-\theta_{L x}}{\theta_{L Y}-\theta_{L x}}\right) \\
0 & -\beta_{1} & A
\end{array}\right]\left[\begin{array}{c}
\hat{Y} \\
\hat{n} \\
\hat{p}
\end{array}\right]=\left[\begin{array}{c}
\sigma \theta_{L s}\left(\gamma_{L s}+\gamma_{L f}\right) \hat{\psi} \\
\sigma \theta_{L s}\left(\gamma_{K s}+\gamma_{K f}\right) \hat{\psi} \\
-(\sigma-1) \beta_{2} \theta_{L s} \hat{\psi}
\end{array}\right]
$$

where A is as defined in A7. Equations (31) and (32) then follow immediately from applying Cramer's rule.

\section{Derivations of (35a) and (35b)}

Let $f$ denote the share of foreign capital in the small open economy-i.e., $f=\frac{\bar{K}_{f}}{\bar{K}_{d}+\bar{K}_{f}}$. Amending (27) to incorporate proportional changes in foreign investment (denoted by $\hat{\bar{K}}_{f}$ ), the three equations-(26), (27), and (30)—can be put in the matrix form as follows: 


$$
\left[\begin{array}{ccc}
\gamma_{L Y} & \gamma_{L x}+\gamma_{L F} & \sigma\left(\gamma_{L s}+\gamma_{L f}\right)\left(\frac{\theta_{L s}-\theta_{L x}}{\theta_{L Y}-\theta_{L x}}\right) \\
\gamma_{K Y} & \gamma_{K x}+\gamma_{K F} & \sigma\left(\gamma_{K s}+\gamma_{K f}\right)\left(\frac{\theta_{L s}-\theta_{L x}}{\theta_{L Y}-\theta_{L x}}\right) \\
0 & -\beta_{1} & A
\end{array}\right]=\left[\begin{array}{c}
\hat{Y} \\
\hat{n} \\
\hat{p}
\end{array}\right]=\left[\begin{array}{c}
\sigma \theta_{L s}\left(\gamma_{L s}+\gamma_{L f}\right) \hat{\psi} \\
\sigma \theta_{L s}\left(\gamma_{K s}+\gamma_{K f}\right) \hat{\psi}+f \hat{K}_{f} \\
-(\sigma-1) \beta_{2} \theta_{L s} \hat{\psi}
\end{array}\right]
$$

Applying Cramer's rule and simplifying subsequently we get (35a) and (35b).

\section{Derivations of (38a) and (38b)}

Note that $T=(1+t)$ where $t>0$ is the ad-valorem tariff rate on imports. Let $\hat{T}$ denote the proportionate change in T (i.e., $\hat{T}=d \ln T$ ). Incorporating $\hat{T}$, equations (28), (29), and (A2) respectively will be modified as

$$
\begin{aligned}
& \hat{P}=\frac{\beta_{1}}{1-\sigma} \hat{n}+\beta_{1} \hat{p}+\beta_{2} \hat{q}+\left(1-\beta_{1}-\beta_{2}\right) \hat{T}, \\
& \hat{z}=\lambda_{w} \hat{w}+\lambda_{r} \hat{r}+\lambda_{t}\left(\hat{t}+\hat{x}^{*}\right)+\lambda_{g} \hat{\pi}_{g},
\end{aligned}
$$

and

$$
\hat{x}^{*}=-\sigma \hat{T}+(\sigma-1) \hat{P}+\hat{z} .
$$

Subtracting (A1) from (A12) yields

$$
\hat{x}^{*}=\sigma(\hat{p}-\hat{T}) .
$$

Substituting (A10), (A11), and (A13) into (A1) and rearranging gives:

$$
A \hat{p}-\beta_{1} \hat{n}+C \hat{T}=-(\sigma-1) \beta_{2} \theta_{L s} \hat{\psi}
$$

where $A$ is as in (A7) while $C=\frac{\lambda_{t}}{t}+(\sigma-1)\left(1-\beta_{1}-\beta_{2}-\lambda_{t}\right)$. Since $1-\beta_{1}-\beta_{2}-\lambda_{t}>$ $0, \mathrm{C}>0$. Equations (26), (27), and (A14) can be written in the matrix form as follows:

$$
\left[\begin{array}{ccc}
\gamma_{L Y} & \gamma_{L x}+\gamma_{L F} & \sigma\left(\gamma_{L s}+\gamma_{L f}\right)\left(\frac{\theta_{L s}-\theta_{L x}}{\theta_{L Y}-\theta_{L x}}\right) \\
\gamma_{K Y} & \gamma_{K x}+\gamma_{K F} & \sigma\left(\gamma_{K s}+\gamma_{K f}\right)\left(\frac{\theta_{L s}-\theta_{L x}}{\theta_{L Y}-\theta_{L x}}\right) \\
0 & -\beta_{1} & A
\end{array}\right]=\left[\begin{array}{c}
\hat{Y} \\
\hat{n} \\
\hat{p}
\end{array}\right]=\left[\begin{array}{c}
\sigma \theta_{L s}\left(\gamma_{L s}+\gamma_{L f}\right) \hat{\psi} \\
\sigma \theta_{L s}\left(\gamma_{K s}+\gamma_{K f}\right) \hat{\psi}+f \hat{K_{f}} \\
-(\sigma-1) \beta_{2} \theta_{L s} \hat{\psi}-C \hat{T}
\end{array}\right]
$$

Then applying Cramer's rule equations (38a) and (38b) follow. 


\section{References}

Anderson, S.P., de Palma A., Thisse, J.-F., 1997. Privatization and efficiency in a differentiated industry, European Economic Review 41, 1635 - 1654.

Antras, P., 2003. Firms, contracts and trade structure, Quarterly Journal of Economics $118,1375-1418$.

Beladi, H., Chao, C., 2006. Mixed ownership, unemployment, and welfare for a developing economy, Review of Development Economics 10, 604-611.

Baland, J.-M., Francois, P., 2005 Commons as insurance and the welfare impact of privatization, Journal of Public Economics 89, 211-231

Barros, F., 1994. Delegation and efficiency in a mixed oligopoly, Annales d'Economie de Statistique 33, 51-72.

Barros, F., Modesto, L., 1999. Portuguese banking sector: a mixed oligopoly?, International Journal of Industrial Organization 17, 869-86.

Bhagwati, J. N., 1968. Distortion and immiserizing growth: a generalization, Review of Economic Studies 35, 481-5.

Boycko, M., Shleifer, A., Vishny, R.W., 1996. A theory of privatization, Economic Journal 106, 309-319.

Brecher, R. A., Diaz-Alejandro, C.F., 1977. Tariffs, foreign capital and immiserizing growth, Journal of International Economics 7, 317-22.

Chakraborty, B. S., 2001, Welfare consequence of capital inflow for a small tariffprotected economy, Journal of Development Economics 66, 305-316.

Clarke, George R.G., Cull, R., 2005. Bank privatization in Argentina: A model of political constraints and differential outcomes, Journal of Development Economics 78, $133-155$.

Cremer, H., Marchand, M., Thisse, J.-F., 1991. Mixed oligopoly with differentiated products, International Journal of Industrial Organization 9, 43-53.

De Fraja, G., 1993. Productive Efficiency in public and private firms, Journal of Public Economics 50, $15-30$.

De Fraja, G., Delbono, F., 1989. Alternative strategies of a public enterprise in oligopoly, Oxford Economic Papers 41, 302-11.

Dewenter, K.L., Malatesta, P.H., 2001. State-owned and privately-owned firms: an empirical analysis of profitability, leverage and labor intensity, American Economic Review 91, 320-34. 
Dutt, P., Mitra, D., 2002. Endogenous trade policy through majority voting: an empirical investigation, Journal of International Economics 58, 107-33.

Feenstra, R. C. (2003) Advanced International Trade: Theory and Evidence, Princeton: Princeton University Press.

Fujiwara, K., 2007. Partial privatization in a differentiated mixed oligopoly, Journal of Economics 92, $51-65$.

Galal, A., Jones, L., Tandon, P., Vogelsang, I., 1994. Welfare Consequences of Selling Public Enterprises: An Empirical Analysis. New York: Oxford University Press.

Grinols, E.L., 1991. Unemployment and foreign capital: the relative opportunity costs of domestic labor and welfare, Economica 58, 107-122.

Hart, O., Shleifer, A., Vishny, R.W., 1997. The proper scope of government: theory and an application to prisons, Quarterly Journal of Economics 112, 1127-61

Helpman, E., Krugman, P.R., 1985. Market Structure and Foreign Trade, Cambridge: MIT Press.

Johnson, H.G., 1967. The possibility of income losses from increased efficiency of factor accumulation in the presence of a tariff, Economic Journal 77, 151-4.

Jones, R. W., 1965. The Structure of Simple General Equilibrium Models. Journal of Political Economy, 73, 557-572.

Majumdar, S. K., 1998. Assessing comparative efficiency of the state-owned, mixed and private sectors in Indian industry, Public Choice 96, 1-24.

Mankiw, N. G., Whinston, M. D., 1986, “Free Entry and Social Inefficiency", RAND Journal of Economics, Vol. 17, pp. 48-58.

Matsumura, T., Kanda, O., 2005. “Mixed Oligopoly at Free Entry Markets.” Journal of Economics 84, 27-48.

Matsumura, T., Matsushima, N., 2004. Endogenous cost differentials between public and private enterprises: a mixed duopoly approach, Economica 71, 671-88.

Megginson, W., Netter, J., 2001. From state to market: a survey of empirical studies on privatization, Journal of Economic Literature 39, 321-89.

Nellis, J., Kikeri, S., 1989. Public enterprise reform: privatization and the World Bank, World Development 17, 659-72.

Roland, G. 2000. Transition and Economics: Politics, Markets and Firms. Cambridge and London: MIT Press.

Saha, B., Sensarma, R., 2004. Divestment and Bank Competition, Journal of 
Economics, 81(3), pp. 223-247

Sachs, J., Warner, A., 1995. Economic reform and the process of global integration, Brookings Papers on Economic Activity, 1-95.

Schmidt, K., 1996. The costs and benefits of privatization: an incomplete contracts approach, Journal of Law, Economics and Organization 12, 1-24.

Sen, P., Ghosh, A. Barman, A., 1997. The possibility of welfare gains with capital inflows in a small tariff-ridden economy, Economica 64, $345-352$.

Suetrong, K., Mukherjee, A., 2009. Privatization, strategic foreign direct investment and host-country welfare, European Economic Review 53, 775-785.

Suzumura, K., Kiyono, K., 1987. Entry Barriers and Economic Welfare, Review of Economic Studies, 54, pp. 157-167.

Venables, A., 1982. Optimal tariffs for trade in monopolistically competitive commodities, Journal of International Economics, 12, 225-41.

Wong, K., 1995. International Trade in Goods and Factor Mobility, Cambridge, MA: MIT Press.

World Bank, 1995. Bureaucrats in Business: The Economics and Politics of Government Ownership. New York: Oxford University Press. 